\title{
A educação pelo trabalho, a educação integral e a Escola Politécnica no Rio Grande do Sul ${ }^{*}$
}

\author{
Vladimir Stolzenberg Torres ${ }^{l}$ \\ Secretaria Estadual de Educação do Rio Grande do Sul
}

Um título sugestivo que traz em si um questionamento, qual seja, será possível integrar educação integral (ou em tempo integral), educação pelo trabalho e a escola politécnica? No Rio Grande do Sul a proposta de ensino politécnico possibilita o questionamento sobre a consorciação de temas que podem ser considerados mutuamente excludentes. É particularmente interessante, resgatar o fato de que uma formação integral que integra educação e trabalho e uma escola de tipo único já faziam parte das idéias dos pensadores clássicos. Marx e Engels teriam retomado tais idéias, a partir das transformações no processo de produção material e simbólico da sociedade moderna. Uma educação que contempla a formação intelectual, corporal e tecnológica do homem, instituída sob um processo de produção técnico-científico, na perspectiva de formação integral. Cabe, portanto, identificar e estabelecer a diferença básica elaborada por Pistrak entre ensino e educação. Em sua concepção, esta possui uma ligação direta com o trabalho social, extinta de uma intencionalidade central, enquanto que o ensino é sistematizado para a transmissão de um determinado tipo de conhecimento. A união estabelecida entre trabalho e ensino é essencial para um projeto que pleiteia a superação do capital, constituindo este, um dos grandes desafios educacionais de nosso tempo.
A suggestive title which brings a question, which is, you can integrate integral education (or full-time), education by work and the polytechnic school? In Rio Grande do Sul the proposal of the polytechnic school allows the question the merging of themes that can be considered mutually exclusive. It is particularly interesting to recover the fact that an integral education which integrates education, work and a unique kind of school that was already part of the ideas of classical thinkers. Marx and Engels would have taken these ideas from the transformations in the material and symbolic of production of the modern society. An education which considers human intellectual, technological and physical formation, established under a process of technical-scientific production, in the perspective of integral formation. It is concerning, therefore, to identify and to establish the basic difference elaborated by Pistrak between teaching and education. In his view, this has a direct connection with social work, which social work its central intention extinguished while education is systematized for the transmission of a particular kind of knowledge. The union established between work and education is essential for a project that pleads to overcome the capital, which constitutes one of the greatest educational challenges of our time.

\footnotetext{
* Education by work, integral education and Rio Grande do Sul Polytechnic School

${ }^{1}$ Trabalho de conclusão da disciplina A docência na escola de tempo integral, do curso de Especialização em Educação Integral da Universidade Federal da Fronteira Sul. Endereço para correspondências: Rua Itapema, número 358, Cachoeirinha, RS, 94950-577 (biologo.vladimir@gmail.com).
} 
Palavras-chave: Educação integral - Escola do trabalho - Escola politécnica.
Keywords: Integral education - Education by work - Polytechnic school.

\section{Introdução}

$\mathrm{O}$ ser humano é integral, é uma síntese de múltiplas relações, de modo que suas necessidades são de ordem material (biológica e física), mas também espirituais e simbólicas. Nesse âmbito se encontram as necessidades e potencialidades éticas e estéticas. A satisfação de tais necessidades nos orienta na construção de relações sociais. Assim, sendo ele um ser de necessidades, então se constitui, também, como um ser de liberdade, mediante relações que buscam a plenitude na satisfação de suas necessidades e das necessidades do outro (RAMOS, 2009).

É consenso, entre os pesquisadores da área de trabalho e educação, que o conceito de "educação politécnica" foi esboçado inicialmente por Karl Marx, em meados do século 19. Em outras palavras, "educação politécnica" pode ser vista como sinônimo de concepção marxista de educação. Cabe esclarecer que, se é originária de Marx a concepção de educação politécnica, o filósofo alemão jamais escreveu um texto sistemático dedicado especificamente à questão pedagógica.

Mas, em que consistiria a educação politécnica para Marx? Pode-se, primeiramente, ilustrar o pensamento marxiano através de uma das passagens mais conhecidas de Karl Marx, retirada das Instruções aos Delegados do Conselho Central Provisório da Associação Internacional dos Trabalhadores, de 1868 (MARX \& ENGELS, 1992): "afirmamos que a sociedade não pode permitir que pais e patrões empreguem, no trabalho, crianças e adolescentes, a menos que se combine este trabalho produtivo com a educação". E, continuando, eles deixam claro o que entendem por educação:

Por educação entendemos três coisas:

1. Educação intelectual.

2. Educação corporal, tal como a que se consegue com os exercícios de ginástica e militares.

3. Educação tecnológica, que recolhe os princípios gerais e de caráter científico de todo o processo de produção e, ao mesmo tempo, inicia as crianças e os adolescentes no manejo de ferramentas elementares dos diversos ramos industriais.

Pode-se facilmente perceber a direção de uma educação multilateral preconizada por Karl Marx; seguindo, o autor aponta a finalidade de sua proposta de educação politécnica: 


\section{A educação pelo trabalho, a educação integral e a Escola Politécnica no Rio Grande do Sul}

Esta combinação de trabalho produtivo pago com a educação intelectual, os exercícios corporais e a formação politécnica elevará a classe operária acima dos níveis das classes burguesa e aristocrática (MARX \& ENGELS, 1992).

Em Celestin Freinet encontra-se a idéia de que o aprendizado deve se dar a partir de ações que sejam necessárias, pela produção de bens que sejam úteis aos aprendizes. Estes tanto podem ser bens materiais - geradores elétricos para iluminar uma escola carente do interior - como bens culturais - poesias, desenhos, jornais e livros escritos e impressos pelos próprios alunos e que seriam, e.g., enviados às escolas das comunidades vizinhas ${ }^{2}$.

Nas indicações, preconizadas por Marx e Engels (1992), encontra-se o embrião fundamental do trabalho como princípio educativo, que busca na transformação radical da sociedade sua última finalidade. Nesse sentido, os principais vetores da concepção marxista de educação são:

1. Educação pública, gratuita, obrigatória e única para todas as crianças e jovens, de forma a romper com o monopólio por parte da burguesia da cultura, do conhecimento.

2. A combinação da educação (incluindo-se aí a educação intelectual, corporal e tecnológica) com a produção material com o propósito de superar o hiato historicamente produzido entre trabalho manual (execução, técnica) e trabalho intelectual (concepção, ciência) e com isso proporcionar a todos uma compreensão integral do processo produtivo. 3. A formação omnilateral (isto é, multilateral, integral) da personalidade de forma a tornar o ser humano capaz de produzir e fruir ciência, arte, técnica. 4. A integração recíproca da escola à sociedade com o propósito de superar a estranhamento entre as práticas educativas e as demais práticas sociais.

\section{No Rio Grande do Sul}

O título se apresenta sugestivo e gera, simultaneamente, um questionamento, qual seja, será possível integrar Educação Integral (ou em Tempo Integral),

\footnotetext{
${ }^{2}$ Encontra-se uma visão similar no trabalho de Makarenko; assim como, também, o trabalho de Paulo Freire tem fortes relações tanto com as propostas de Freinet como com as de Makarenko. A idéia dos conceitos geradores como ponto de partida para um ensino libertador tem evidente ligação com os trabalhos desenvolvidos pelos dois educadores. Ver Capriles (1989) para uma descrição do trabalho e da importância de Makarenko para quase todos os educadores de nosso século.
} 


\section{HUM AN AS}

Educação pelo Trabalho e a Escola Politécnica? No Rio Grande do Sul, existe a proposta, ainda não consolidada, de implantação gradual da Politecnia para o Ensino Médio (PATTA, 2011) onde não haja formação profissional (Curso Normal e/ou Cursos Técnicos), o que permite que se realize uma discussão sobre a possibilidade de consorciar temas que possam, em um primeiro momento, se apresentar até mesmo como mutuamente excludentes.

Na prática, por outro lado, também as escolas que mantenham ensino médio com formação estão sendo atingidas, haja vista a ampliação de sua carga horária anual de oitocentas convencionais para mil horas.

No que tange a Educação Integral, observa-se que uma das principais metas do Plano Nacional da Educação, instituído em 2001, é a ampliação da jornada escolar para um período mínimo de 7 horas. Apesar da questão conceitual ainda estar em construção, ela pode ser entendida como um ensino que possibilita uma formação mais completa para o aluno enquanto ser humano e não apenas como estudante. Trabalhar com essa perspectiva significa conciliar o conteúdo didático com outras peculiaridades da vida. Este aspecto, então, coaduna com a Lei Federal N ${ }^{\circ}$ 9.394, de 20 de dezembro de 1996, segundo a qual:

Art. 22. A educação básica tem por finalidades desenvolver o educando, assegurar-lhe a formação comum indispensável para o exercício da cidadania e fornecer-lhe meios para progredir no trabalho e em estudos posteriores.

Art. 35. O ensino médio, etapa final da educação básica, com duração mínima de três anos, terá como finalidades:

$\mathrm{I}-\ldots$

II - a preparação básica para o trabalho e a cidadania do educando, para continuar aprendendo, de modo a ser capaz de se adaptar com flexibilidade a novas condições de ocupação ou aperfeiçoamento posteriores;

III - o aprimoramento do educando como pessoa humana, incluindo a formação ética e o desenvolvimento da autonomia intelectual e do pensamento crítico; IV - a compreensão dos fundamentos científico-tecnológicos dos processos produtivos, relacionando a teoria com a prática, no ensino de cada disciplina.

Porém, considerando a questão da ampliação da "jornada escolar", qual deve ser efetivamente o papel da escola neste novo contexto? Na visão da Cavaliere (2002), a ampliação das funções da escola, de forma a melhor cumprir um papel sócio-integrador, vem ocorrendo por urgente imposição da realidade, 


\section{A educação pelo trabalho, a educação integral e a Escola Politécnica no Rio Grande do Sul}

e não por uma escolha político-educacional deliberada. Entretanto, a institucionalização do fenômeno pelos sistemas educacionais, que já desponta em políticas públicas, envolverá escolhas, isto é envolverá concepções e decisões políticas. Tanto poderão ser desenvolvidos os aspectos inovadores e transformadores embutidos numa prática escolar rica e multidimensional, como poderão ser exacerbados os aspectos reguladores e conservadores inerentes às instituições em geral.

Assim, o sentido do ensino em uma educação voltada para a escola do trabalho está intrínseco ao objetivo que lhe é dado. Neste tipo de escola o ensino possui a finalidade de reunir conhecimentos capazes de desenvolver na criança aptidões com as quais ela possa interpretar a realidade, reconhecendose enquanto sujeito histórico de seu tempo, hábil a transformar a realidade na qual está inserida. Desta forma:

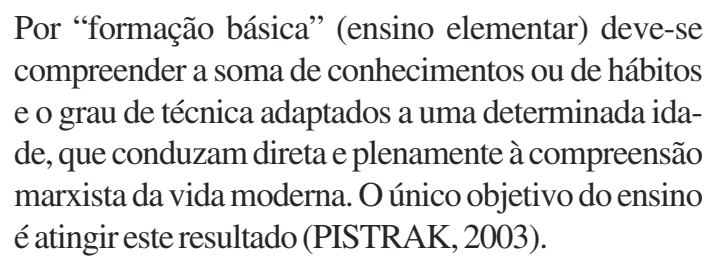

Conforme Ramos (2009), antes de ser específico, porém, na forma de subordinação ao capital, pelas quais o trabalhador não opta autonomamente pelo tipo de trabalho com o qual produzirá sua existência, o trabalho define a própria natureza humana e social do ser; por isso, ele é contraditório, o que nos exige percebê-lo como necessidade e potencialidade humanas.

Ainda segundo Ramos (op. cit.), o trabalho é, então, uma característica ontológica do ser. Se o trabalho é inerente ao ser como meio de produção de sua existência, ele tem também um sentido histórico. Ou seja, o trabalho assume formas específicas ao longo da história da humanidade, de acordo com o processo de produção que se organiza socialmente.

Não há como se pensar e realizar o trabalho para um ser humano assistido integralmente se não houver o auto reconhecimento, também como ser integral. É nesse sentido que se aborda o trabalho como princípio educativo, diferenciando-o do princípio educativo que fundamenta estratégias metodológicas baseadas no aprender fazendo. Talvez, como princípio pedagógico, ele esteja muito presente em nosso cotidiano.

\section{A convergência}

Por outro lado, de acordo com Cavaliere (2002), a ampliação do tempo diário do aluno na escola pode ser compreendida com uma forma de melhorar o rendimento escolar, como uma adequação da rotina urbana contemporânea, 


\title{
HUM ANAS
}

em que a escola serve para atender a esta demanda, ou como uma nova concepção de educação escolar, em que a escola desempenhe o papel de formação na vida dos indivíduos.

É particularmente interessante, resgatar o fato de que uma formação integral que integra educação e trabalho e uma escola de tipo único já faziam parte das idéias dos pensadores clássicos. Marx e Engels (1992) estariam retomando tais idéias, a partir das transformações no processo de produção material e simbólico da sociedade moderna. A concepção de educação marxiana compreende três aspectos:

\begin{abstract}
Educação intelectual; educação corporal, tal como a que se consegue com os exercícios de ginástica e militares; educação tecnológica, que recolhe os princípios gerais e de caráter científico de todo o processo de produção e, ao mesmo tempo, inicia as crianças e os adolescentes no manejo de ferramentas elementares dos diversos ramos industriais (MARX \& ENGELS, 1992).
\end{abstract}

Uma educação que contempla a formação intelectual, corporal e tecnológica do homem, instituída sob um processo de produção técnico-científico, na perspectiva de formação integral. Assim, conforme Pistrak (2003), os conteúdos necessários das disciplinas deveriam ser introduzidos com estudos que levassem a compreensão da realidade atual, das estruturas e engrenagens da sociedade capitalista e das necessidades da construção do socialismo. A Revolução Russa (1917) possibilitou o debate acerca da teoria materialista de educação, que se apresentou com uma formulação teórico-pedagógica a qual compreende a formação integral do homem, a partir da vinculação do ensino com o trabalho produtivo.

A concepção de formação integral marxiana toma a superação da divisão do trabalho, a união do trabalho manual ao trabalho intelectual e o processo histórico-concreto de construção da sociedade, sob o qual a formação integral se constrói. A perspectiva é de que esta formação integral leve os trabalhadores ao domínio científico e tecnológico do novo processo de produção em curso, e propicie as condições para a construção de uma estrutura social, na qual os trabalhadores se constituam como classe dirigente.

Nesta óptica, a Educação Integral, pela valorização da convivência, da interação e do trabalho conjunto, obriga a escola a rever-se também como espaço do contraditório, das experiências de conflito e de antagonismos; um espaço que acolhe as diferenças. A auto-análise feita pela escola busca soluções para articular as polaridades que constituem o todo, unidade complexa que compõe o homem integral. A Educação Integral só poderá acontecer verdadeiramente se considerar a complexidade humana. 


\section{A educação pelo trabalho, a educação integral e a Escola Politécnica no Rio Grande do Sul}

Neste contexto, tornam-se convergentes a proposta do governo gaúcho e àquela, que se evidencia na obra de Pistrak e de educadores Russos que vivenciaram o momento revolucionário naquele país (Krupskaia, Makarenko, Lunatcharsky), sendo então notório o trabalho de pesquisa, debates e militância para a formulação de teorias pedagógicas que contribuíssem para a construção de uma educação escolar coerente com a novíssima tentativa de organização da classe trabalhadora a partir da revolução de Outubro/1917.

Saviani define educação politécnica como "o domínio dos conhecimentos científicos das diferentes técnicas que caracterizam o processo de trabalho produtivo moderno" (Saviani, apud Frigotto et al., 2005). Pistrak, assim como Saviani (2001), coloca o trabalho como categoria fundante do ser social, necessária a existência da educação, justamente, por ser o trabalho seu elemento base. Assim, o trabalho apresenta-se à escola como categoria necessária ao processo educativo, independente da lógica estabelecida.

Mas é fato que diante da estrutura como está organizada a sociedade brasileira na atualidade, esta educação politécnica, que não previa ingresso do mundo da produção antes de completar a formação, tornou-se uma perspectiva a vir a ser realizada. Como alternativa possível, surge a idéia de articular a educação geral com eixos estruturantes como base para uma futura educação tecnológica ou politécnica, mas, também, a possibilidade de formação profissional para a população (jovens trabalhadores) que necessita ter acesso a formas dignas de subsistência. Assim surge a concepção de conversão da atual escola de ensino médio para a modalidade politécnica, através da qual, o Ensino Médio seria melhor vinculado à realidade social e ao desenvolvimento científico-tecnológico, integrando as áreas do conhecimento (linguagens, matemática, ciências da natureza e ciências humanas). Nesta linha, o Conselho Nacional de Educação (CNE), por meio da Câmara de Educação Básica, assim se posiciona:

\footnotetext{
O Ensino Médio deve ter uma base unitária sobre a qual podem se assentar possibilidades diversas como preparação geral para o trabalho ou facultativamente, para profissões técnicas; na ciência e na tecnologia, como iniciação científica e tecnológica; na cultura como ampliação da formação cultural (CNE/CEB, Resolução ${ }^{\circ}$ 4/ 2010, Art. 26, $\left.\S 1^{\circ}\right)$.
}

Seguindo neste pensamento, o objetivo da escola, portanto, é formar para a aquisição de experiências que tornem as crianças trabalhadores completos. O problema se resume da seguinte forma: 
1. A escola deve dar aos alunos uma formação básica social e técnica suficiente para permitir uma boa orientação prática na vida; 2 . ela deve assumir antes de tudo um caráter prático a fim de facilitar ao aluno a transição entre a escola e a realidade integral da existência, a fim de capacitá-lo a compreender seu meio e a se dirigir autonomamente; e 3. ela deve acostumá-lo a analisar e a explicar seu trabalho de forma científica, ensinando-lhe a se elevar do problema prático à concepção geral teórica, a demonstrar iniciativa na busca de soluções (PISTRAK, 2003).

Pondo o trabalho como diretriz da educação, Pistrak afirmava ser necessário um programa de ensino que estabelecesse o trabalho como base escolar, pois ao ensino deveria ser atribuído o objetivo de sistematizar o conhecimento vinculado ao trabalho, para que este pudesse ser enraizado na escola.

Esta concepção evidencia uma profunda articulação entre as áreas de conhecimento e seus componentes curriculares com as dimensões Ciência, Cultura, Tecnologia e Trabalho. Esta articulação deve se explicitar no desenvolvimento de ações, atividades e vivências pedagógicas, com vista a modificar a relação atual entre trabalho e trabalhador. Nessa perspectiva, pretende-se que, no seu cotidiano, o trabalhador não fique subordinado ao desenvolvimento de habilidades específicas e a práticas laborais mecânicas, mas incorpore nas suas atividades profissionais os fundamentos científicos que as sustentam. Isso significa que, antes de aprender algum oficio nos seus aspectos práticos e imediatos, é fundamental a mediação política para sua contextualização como fenômeno histórico e suas perspectivas futuras (SEDuc, 2011).

Na versão geral, o Ensino Médio Politécnico, embora não profissionalize, deve estar enraizado no mundo do trabalho e das relações sociais, de modo a promover formação científico-tecnológica e sócio-histórica a partir dos significados derivados da cultura, tendo em vista a compreensão e a transformação da realidade. Do ponto de vista da organização curricular, a politecnia supõe novas formas de seleção e organização dos conteúdos a partir da prática social, contemplando o diálogo entre as áreas de conhecimento; supõe a primazia da qualidade da relação com o conhecimento pelo protagonismo do aluno sobre a quantidade de conteúdos apropriados de forma mecânica; supõe a primazia do significado social do conhecimento sobre os critérios formais inerentes à lógica disciplinar (SEDuc, op. cit.).

A politecnia, conforme Laudares e Gonçalves (2007) constitui-se no domínio científico e técnico ou seja, tecnológico dos processos produtivos. 


\section{A educação pelo trabalho, a educação integral e a Escola Politécnica no Rio Grande do Sul}

Para o trabalhador significaria a superação da divisão do trabalho intelectual e manual e a apropriação técnica e científica dos processos de produção. A Escola do Trabalho, portanto, constituiu-se tomando o trabalho como ponto de partida e buscando concretizar a educação politécnica.

A convergência entre educação integral, Pistrak e escola politécnica fica particularmente evidente quando se realiza uma leitura de Marx (2002) para se perceber que a luta por uma educação integral que conjugue trabalho e educação, ciência e técnica e substitua o indivíduo parcial por um indivíduo integral, se insere no contexto maior de luta pelo poder político da classe operária sendo que, para atingi-lo esta terá que sair da situação de "reserva para as necessidades flutuantes da exploração capitalista" para tornar-se classe possuidora de "indivíduos integralmente desenvolvidos" e com disponibilidade absoluta para "as necessidades variáveis do trabalho".

\section{Considerações finais}

Antes de qualquer coisa, é necessário que tenhamos a compreensão de que cada problema educacional deve ser analisado no contexto histórico do qual faz parte, para não cometeremos equívocos em nossas análises a cerca da educação. Pistrak situava-se em um contexto que lhe permitia, e era necessário, a concretização de uma nova concepção de educação. Porém, é inegável a contemporaneidade de sua teoria, que apesar de não adaptar-se completamente a atualidade de nossas escolas, há de contribuir para nossas análises educacionais.

Conforme Maimone e Vieira (2009), dentro do processo de grupos operativos, por exemplo, professores, funcionários e alunos ensinam e aprendem numa interação social, na qual o indivíduo possa se conhecer e ser capaz de compreender a importância e as reações do outro, tornando o espaço escolar um espaço significativo para cada um e para o coletivo das pessoas. Segundo Vieira (2003), isso se reflete no desempenho escolar dos alunos em regime de tempo integral, quando comparados aos seus colegas que, na mesma escola, não passaram por todo esse processo formativo.

Portanto, a educação do trabalhador que vise uma Formação Integral, e que lhe proporcione o domínio científico e tecnológico do processo produtivo; deve se constituir em uma educação intelectual, corporal, política e social, que precisa tomar o estudo e análise do trabalho e da vida no contexto contraditório do modo de produção capitalista, no qual o trabalho transforma e deforma o trabalhador.

A formação pelo trabalho, então, implica necessariamente uma apropriação de conhecimentos que permita ao sujeito conhecer e reconhecer a totalidade do processo do trabalho, ainda que ele venha a atuar em uma parte dessa totalidade. 


\section{H UM ANAS}

Nesta óptica, por conseguinte, surge como complementar a uma educação integral, onde favorece ao indivíduo o apropriar concreto da realidade sóciocultural que o circunscreve. Nesta apropriação, ele passa a se aproximar da perspectiva de escola unitária apontada por Gramsci, o que requer uma educação geral que se torne parte inseparável da educação profissional, e que o trabalho seja o princípio educativo na perspectiva de incorporar a dimensão intelectual ao trabalho produtivo.

Cabe, portanto, identificar e estabelecer a diferença básica elaborada por Pistrak entre ensino e educação. Em sua concepção, esta possui uma ligação direta com o trabalho social, extinta de uma intencionalidade central, enquanto que o ensino é sistematizado para a transmissão de um determinado tipo de conhecimento. A união estabelecida entre trabalho e ensino é essencial para um projeto que pleiteia a superação do capital, constituindo este, um dos grandes desafios educacionais de nosso tempo.

\section{Referências bibliográficas}

CAPRILES, R. Makarenko - O nascimento da pedagogia socialista. São Paulo: Scipione. 1989.

CAVALIERE, A.M.V. Educação Integral: uma nova identidade para a escola brasileira? Educação e Sociedade, 23(81): 247-70. 2002.

CNE. Conselho Nacional de Educação/Câmara de Educação Básica. Resolução $n^{\circ} 4$, de 13 de julho de 2010, a qual define diretrizes curriculares nacionais para educação básica.

FRIGOTTO, G.; CIAVATTA, M. \& RAMOS, M. O trabalho como princípio educativo. In: H. COSTA \& M. DA CONCEIÇÃO (Org). Educação integral e sistema de reconhecimento e certificação educacional e profissional. São Paulo: CUT, 2005.

IBGE. Pesquisa Nacional por Amostra de Domicílio 2009. Disponível em [http:/ /www.ibge.gov.br/home/estatistica/populacao/trabalhoerendimento/pnad2009/ default.htm]. Acesso em 2011.

LAUDARES, J.B. \& GONÇALVES, A. A pedagogia da escola do trabalho e a formação integral do trabalhador. Revista Brasileira de Estudos Pedagógicos, 88(220): 516-30, 2007.

MAIMONE, E.H. \& VIEIRA, V.M. de O. Grupos operativos na formação de professores em escola de tempo integral. Revista da Associação Brasileira de Psicologia Escolar e Educacional, 13(1): 183-84. 2009. 
MARX, K. O capital: crítica da economia política. $19^{a}$ Edição, Livro I, volume 1. Rio de Janeiro: Civilização Brasileira, 2002.

MARX, K. \& ENGELS, F. Textos sobre educação e ensino. São Paulo: Editora Moraes, 1992.

PATTA, R. O futuro do ensino médio com a nova grade curricular: Mudanças passam a valer a partir do início do ano letivo de 2012 e será implantada gradativamente até 2014. Jornal Gazeta do Sul, 19 de Novembro de 2011.

PISTRAK, M.M. Fundamentos da escola do trabalho. São Paulo: Expressão Popular, 2003.

RAMOS, M. Educação pelo trabalho: possibilidades, limites e perspectivas da formação profissional. Saúde e Sociedade, 18(Supl. 2): 55-59, 2009.

SAVIANI, D. Escola e democracia. Campinas: Autores Associados, 2001.

SEDuc. Secretaria Estadual de Educação do RS. Proposta Pedagógica para o Ensino Médio Politécnico e Educação Profissional Integrada ao Ensino Médio 2011-2014. Porto Alegre, SEDuc, 2011.

VIEIRA, V.M. de O. Escola de tempo integral: buscando evidências de um ensino de qualidade. Dissertação de Mestrado. Uberaba/MG: Universidade de Uberaba, 2003. 